WellBeing International

WBI Studies Repository

3-2014

\title{
Learning and Memory in the Port Jackson Shark, Heterodontus portusjacksoni
}

\author{
Tristan L. Guttridge \\ Macquarie University \\ Culum Brown \\ Macquarie University
}

Follow this and additional works at: https://www.wellbeingintlstudiesrepository.org/acwp_asie

Part of the Animal Studies Commons, Comparative Psychology Commons, and the Other Animal Sciences Commons

\section{Recommended Citation}

Guttridge, T. L., \& Brown, C. (2014). Learning and memory in the Port Jackson shark, Heterodontus portusjacksoni. Animal cognition, 17(2), 415-425.

This material is brought to you for free and open access by WellBeing International. It has been accepted for inclusion by an authorized administrator of the WBI Studies Repository. For more information, please contact wbisr-info@wellbeingintl.org.

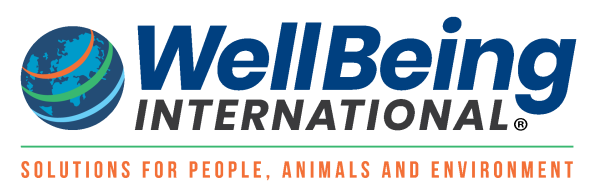




\title{
Learning and memory in the Port Jackson shark, Heterodontus portusjacksoni
}

Tristan L. Guttridge and Culum Brown

Macquarie University

\section{KEYWORDS}

classical conditioning, associative learning , Benthic shark, heterodontiformes

\begin{abstract}
Basic understanding of the fundamental principles and mechanisms involved in learning is lacking for elasmobranch fishes. Our aim in this study was to experimentally investigate the learning and memory capacity of juvenile Port Jackson sharks, Heterodontus portusjacksoni. Sharks $(N=30)$ were conditioned over a 19-day period to associate an underwater LED light or stream of air-bubbles [conditioned stimulus (CS)] with a food reward [unconditioned stimulus (US)], using three procedures (delay, trace and control). During experiments, the CS signalled at a random time between 180 and $300 \mathrm{~s}$ for $30 \mathrm{~s}$ (six times per day). For the delay the US overlapped in time with the CS, for the trace the US delivered $10 \mathrm{~s}$ after the CS and for our control the US was delivered at random time between 180 and $300 \mathrm{~s}$ after the CS. $H$. portusjacksoni sharks trained in all procedures improved consistently in their time to obtain food, indicative of Pavlovian learning. Importantly, the number of sharks in the feeding area $5 \mathrm{~s}$ prior to CS onset did not change over time for any procedures. However, significantly more sharks were present $5 \mathrm{~s}$ after CS onset for delay for both air-bubble and light CS. Sharks trained in the delay and trace procedures using air-bubbles as the CS also displayed significantly more anticipatory behaviours, such as turning towards the CS and biting. Sharks trained with the light CS did not exhibit such behaviours; however, trace procedural sharks did show a significant improvement in moving towards the CS at its onset. At 20 and 40 days after the end of the conditioning experiments, some sharks were presented the CS without reward. Two sharks trained in the delay procedure using air-bubbles as the CS exhibited biting behaviours: one at 20 and the other at 40 days. This study demonstrates that $H$. portusjacksoni have the capacity to learn a classical conditioning procedure relatively quickly (30 trials during 5 days) and associate two time-separated events and retention of learnt associations for at least $24 \mathrm{~h}$ and possibly up to 40 days.
\end{abstract}

\section{Introduction}

Learning, or the adaptive modification of behaviour based on experience, affects virtually every aspect of animal behaviour (Pearce and Bouton 2001). It allows an animal to develop, within its lifetime, an adaptive response to a completely novel situation that has potentially never been encountered in the species evolutionary past (Kawecki 2010). Studies investigating learning in fishes are widespread, having important implications for behaviour and fisheries as well as expanding our knowledge of how these 
processes evolved across the vertebrate lineage (Brown et al. 2011). More recently, its significance has also been highlighted for elasmobranch fishes (Guttridge et al. 2009) with notable demonstrations of social (Guttridge et al. 2013) and spatial learning (Schluessel and Bleckmann 2005, 2012). However, despite these efforts, surprisingly little is known about the fundamental learning capacities of this class of marine vertebrates (Guttridge et al. 2009).

Nature provides a vast amount of sensory information that animals use to make decisions regarding behaviours such as what to eat or where to hide. Learning an association between events is essential because it allows animals to identify which event predicts the next and to respond to imminent biologically significant events more effectively (Hollis 1984; Nilsson et al. 2008a). Having the ability to learn an association with a stimulus, such as visual feature and odour of an approaching predator, for example, might increase the animal's attention and preparedness to flee, thus increasing survival. In natural situations, events can overlap (i.e. sight of predator and then attack) or be separated in time (i.e. sight of fleeing individual indicating a predator might appear in the near future); thus, being able to learn associations with different temporal relationships would therefore be advantageous (Nilsson et al. 2008b).

Associative learning occurs when an association or relationship between two events is established. In classical conditioning, a neutral stimulus [conditioned stimulus (CS)], such as a light, signals the delivery of a biologically significant event [unconditioned stimulus (US)], such as food (Lieberman 1990). Evidence of learning is considered when the CS elicits a response [conditioned response (CR)], which is appropriate to the imminent delivery of the US (Pearce and Bouton 2001). Since the classic experiments of Pavlov (1927), we have known that associative conditioning is most efficient when the CS-US presentations overlap in time, i.e. delay conditioning. However, the addition of a simple pronounced temporal gap between the CS and US, i.e. trace conditioning, can have profound effects on learning (Perisse and Waddell 2011). Subjects usually need more trials to acquire trace conditioning, and it is also known to recruit additional neural structures in mammals and insects, such as the hippocampus and mushroom body, respectively (Woodruff-Pak and Disterhoft 2008; Shuai et al. 2011). Interestingly, recent studies have found evidence for trace conditioning in a number of fish species including rainbow trout (Oncorhynchus mykiss), goldfish (Carassius auratus auratus), Atlantic cod (Gadus morhua) and halibut (Hippoglossus hippoglossus), with the latter two species being able to associate events that occur with a time gap of at least 60 s (Portavella et al. 2004; Nilsson et al. 2008a, b, 2010; Nordgreen et al. 2010).

Sharks' capacity to learn was originally demonstrated using an operant conditioning regime (Clark 1959) and then later extended to include acoustic (Nelson 1967) and visual discrimination learning (Tester and Kato 1966). Gruber and Schneiderman (1975) reported the first authoritative account of classical conditioning in juvenile lemon sharks (Negaprion brevirostris). Training involved restraining the shark while exposing it to a light flash (CS) that was paired with an electric shock (US), producing an eye-blink response. These experiments suggested that sharks were able to learn discriminative tasks as rapidly as other vertebrates displaying comparable learning characteristics, such as gradual recovery when exposed to extinction sessions (Schneiderman and Gormezano 1964; Aronson et al. 1967). Since these early demonstrations, however, conditioning techniques have been primarily used as a tool to investigate sensory thresholds (Guttridge et al. 2009). Little if any information is known about the learning abilities of benthic sharks (Malyukova et al. 1983), and to our knowledge, no study has explored trace conditioning for any elasmobranch fish despite their position at the base of the vertebrate evolutionary tree.

Surviving in complex and fluctuating environments is challenging for animals. Having the ability to retain information about where to find or how to handle prey might increase foraging efficiency (Brown et al. 2011). Indeed, there are examples from various taxa of animals displaying impressive feats of memory; turtles (Pseudemys nelson) learnt and retained a novel food acquisition task for 7 months; corvid birds (Nucifraga columbiana) remembered 18-25 caches in a room containing 69 cache sites for as long as 9 
months, and rainbowfish (Melanotaenia duboulayi) learnt to avoid trawl apparatus in the laboratory with avoidance persisting for at least 11 months (Brown and Laland 2001). More recently, a number of studies on teleost fishes have explored this further (Nilsson et al. 2008a, b, 2010; Tlusty et al. 2008; Zion et al. 2011), finding memory windows from 3 to 7 months for both trace and delay conditioning procedures, using acoustic and visual CS. Few studies have investigated memory capacity in elasmobranch fishes. The earliest documentation was of two adult lemon sharks that retained an operant conditioning response for up to 10 weeks (Clark 1959) with further speculations using visual discrimination training on nurse sharks (Ginglymostoma cirratum) (Graeber et al. 1973). More recently, Schluessel and Bleckmann (2012) investigated memory retention capabilities of spatial learning tasks in the grey bamboo shark (Chiloscyllium griseum), finding that some individuals retained spatial information for up to 6 weeks in the absence of reinforcement. However, we still understand very little about memory retention in elasmobranch fishes even though such capabilities are most likely widespread given their k-selected life history traits and evidence for site fidelity and prey selectivity (Grubbs 2010; Speed et al. 2010).

Port Jackson sharks (Heterodontus portjacksoni) are a medium-sized $(<1.6 \mathrm{~m}$ ), epibenthic species from a primitive order, the heterodontiformes that are endemic to Australia (Last and Stevens 2009). They have a broad diet and are often found aggregating close to reef structures (McLaughlin and O'Gower 1971; Powter et al. 2010) with juveniles and adults displaying high site fidelity to specific core areas (Powter and Gladstone 2009). O'Gower (1995) speculated that Port Jackson sharks have impressive spatial memory capabilities using visual features of reef topology to return $24 \mathrm{~h}$ later after being displaced from their resting sites. At our study site (Merimbula, NSW), juveniles (10.8 m) are abundant and have been successfully used in captive experimental studies (Peach 2001). These characteristics make the Port Jackson shark an excellent model species to experimentally investigate fundamental learning principles in elasmobranch fishes.

The purpose of this study was to investigate the learning and memory capacity of juvenile Port Jackson sharks. To do this, individual sharks were conditioned over a 19-day period to associate an underwater light or stream of air bubbles (CS) with a food reward (US) to procedures: (1) delay (i.e. overlapping CSUS), (2) trace (i.e. CS-US with short time interval, $10 \mathrm{~s}$ ) and (3) control (i.e. US delivered at random time). Using this learning paradigm, we were able to determine whether Port Jackson sharks had the capacity for delay and/or trace conditioning and if so, whether the memory of the learnt CS-US association persisted over short (24 h) and possibly long (20-40 days) time periods. We also explored whether using a more biologically relevant CS influenced learning performance and expression of the CR. We predicted that Port Jackson sharks would be able to learn both delay and trace conditioning regimes using light or air-bubble as the CS and demonstrate retention of these at various time scales in the absence of reinforcement. More specifically, after training we expected sharks to exhibit CRs, with stimulus substitution leading to movement towards CS at onset and with feeding type behaviours directed towards the CS prior to US delivery. These responses were expected to be more frequent and pronounced in our sharks trained to the delay regime as seen in other fishes (Nilsson et al. 2008a, b, 2010). Port Jackson sharks are considered nocturnal, feeding primarily on small invertebrates that are buried in the sediment (Powter et al. 2010); thus, we also expected sharks trained to the air-bubble CS to exhibit more pronounced and persistent CRs than those trained to the light CS.

\section{Materials and methods}

\section{Study location and study sharks}

The study was conducted at Merimbula Aquarium, NSW, Australia. Port Jackson sharks were our test subjects because of their abundance along the NSW coast, renowned hardiness in captivity and small body size (Peach 2001; Powter and Gladstone 2009). A total of 30 juvenile Port Jackson sharks (mean 
standard length \pm standard deviation $=43 \pm 3 \mathrm{~cm}$ ) were obtained from the bycatch of a commercial fisher. Sharks were collected in batches $(n=6-10)$ every 3-4 weeks, a few days prior to the start of experiments. They were assessed for good condition, transported and then housed in two outdoor flowthrough seawater tanks $(2,000 \mathrm{I})$. On arrival, each shark was restrained in a trough $(0.190 .6 \mathrm{~m})$ to allow tagging, weighing $(\mathrm{g})$ and measurement $(\mathrm{cm})$. Sharks were marked with a unique colour-code tag to provide external individual identification (T-bar type, Hallprint Ltd), through the first or second dorsal fin.

After $24 \mathrm{~h}$ in captivity, all sharks were fed $2 \%$ of their body weight in squid (Loligo opalescens) pieces, a daily recommended allowance to sustain benthic shark species (Sims 1996). Sharks were released if they did not feed within 3 days of arrival. During non-experimental periods, sharks were fed to satiation every 3 days on mixed diet of frozen squid and pilchard (Sardinops neopilchardus) pieces. Sharks were moved using nets and transported between tanks in plastic tubs (50 I). No sharks died during the experiments and all were weighed on release close to their capture site. We detected no significant difference between start and end weight, Wilcoxon signed-ranks test, P[0.1. An ethics permit (ARA 2010/041) to conduct scientific marine research was obtained from Macquarie University, Australia.

\section{Experimental set-up}

A seawater flow-through aquarium ( $2.5 \mathrm{~m}$ long, $1.5 \mathrm{~m}$ wide and $1 \mathrm{~m}$ deep) was used to train and house experimental subjects. Water temperature was maintained at $16-18{ }^{\circ} \mathrm{C}$, and low-level aquarium lighting was provided during natural daylight hours. Plastic opaque barriers were fitted with supporting rocks to partition the tank into three main compartments: (1) holding area with gravel and rocky substrate to house the sharks in between daily experiments, (2) experimental area split into four sections (1-4) with the conditioned stimulus (CS) located in the top left corner of section 4 and feeding apparatus to deliver the unconditioned stimulus (US) ${ }^{*} 1 \mathrm{~cm}$ in front of the CS and (3) start box used to hold sharks in between experimental trials fitted with sliding doors to control the movement of sharks between compartments (Fig. 1). The inflow was placed in the holding area and outflow in the experimental area removing olfactory cues emitted from the US between trials. A video camera linked to a monitor (out of view of the tank) was positioned above the experimental area providing full coverage (Fig. 1).

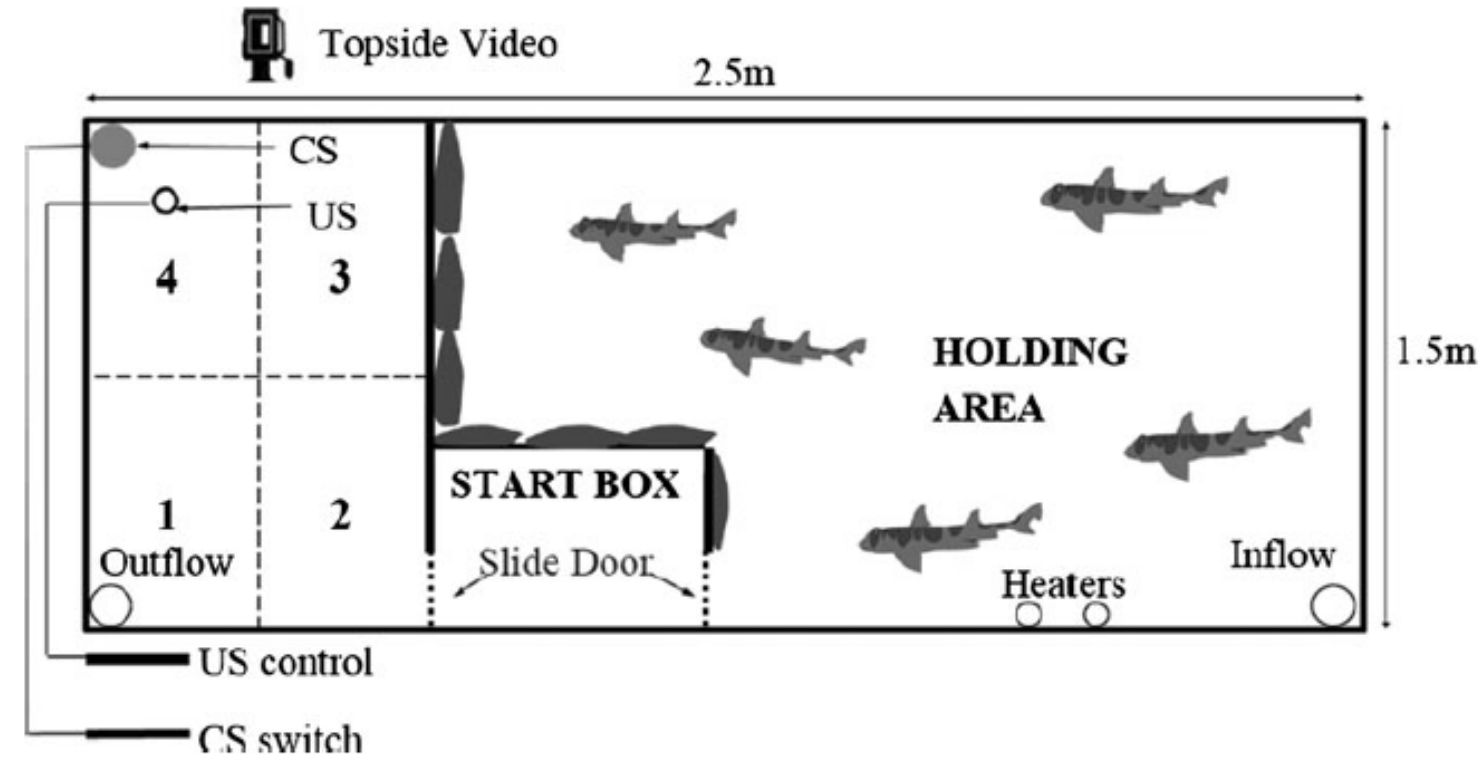

Fig. 1 Experimental set-up 

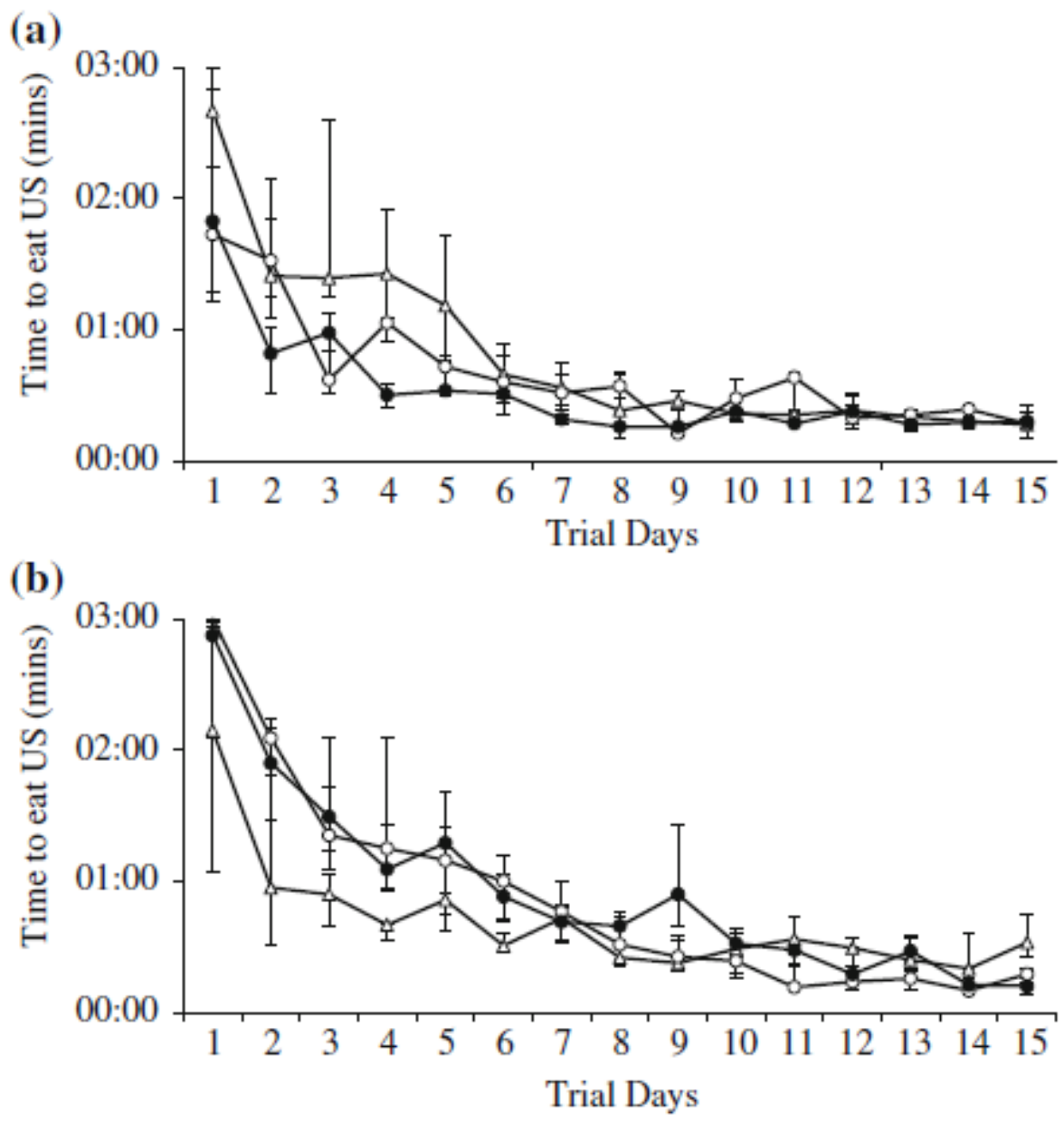

Fig. 2 Median ( \pm IQR) time to consume US during delay (empty circles), control (filled circles) and trace (empty triangles) procedures for a light CS and b air-bubble CS. $n=5$ per procedure

\section{Experimental protocol}

Sharks ( $N=30)$ were randomly assigned to CS treatments: (1) underwater LED spot light (1.5 W, Prisma LED, Australia) or (2) air-bubbles (plastic tube connected to an air pump) and then to procedures: (a) delay, (b) trace and (c) control. Each CS was manually operated and signalled for $30 \mathrm{~s}$ using a digital timer. The US was a food reward (squid piece; pre-cut and weighed) loosely attached to monofilament that was controlled manually and weighed down by a sinker. Sharks were trained in groups of four to six over a period of 19 days according to the following schedule: Day 1-acclimation, Days 2-10-training, Day 11-memory retention trial, Days 12-17-training, Day 18-memory retention trial, and Day 19relocation or release (see Table 1 for experimental steps). During the acclimatisation period, all compartments were opened for exploration, and on completion, sharks were ushered to the holding area. An individual shark was then selected and ushered from the holding area into the start box for testing. After $60 \mathrm{~s}$, the sliding door leading to the experimental arena was opened, and the test shark was given $30 \mathrm{~s}$ to emerge from the start box. If $30 \mathrm{~s}$ passed, the shark was gently ushered into the experimental arena. The door to the start box was then closed. 
For all procedures, the CS signalled at a random time between 180 and $300 \mathrm{~s}$ for $30 \mathrm{~s}$. For the delay treatment, the US was delivered $15 \mathrm{~s}$ after the onset of the CS. For the trace treatment, the US was delivered $10 \mathrm{~s}$ after CS termination, and for the control treatment, the US was delivered at a random time between 180 and $300 \mathrm{~s}$ after CS. Sharks were given $180 \mathrm{~s}$ to consume the reward and after consumption were ushered back into the start box and given $60 \mathrm{~s}$ until the start of the next trial. Each shark completed six trials per day, except on memory retention trials when only one was completed without the US. Individual shark total daily food intake was equivalent to $2 \%$ of their body weight, divided equally among the six trials. All experiments were completed in daylight hours ( $8 \mathrm{am}-5 \mathrm{pm})$, and individual sharks completed their trials at a similar time each day to allow for $24 \mathrm{~h}$ between feeds, ensuring motivation was consistent.

Table 1 Description of experimental steps

\begin{tabular}{|c|c|}
\hline Task & Description \\
\hline Shark capture & Sharks captured, processed and housed in flow-through tanks \\
\hline Captive acclimation & Sharks given $24 \mathrm{~h}$ and fed to satiation to ensure motivation to feed in captivity \\
\hline Day 1: Experimental acclimation & $\begin{array}{l}\text { Start of 19-day experimental trial period. Sharks moved to experimental tank and } \\
\text { given } 24 \mathrm{~h} \text { to move between all sections }\end{array}$ \\
\hline Day 2-10 and 12-17: Training & $\begin{array}{l}\text { Individual sharks completed six trials per day trained to the CS and procedure that } \\
\text { they were assigned to (see "Materials and Methods" section) }\end{array}$ \\
\hline Day 11 and 18: Memory trials & Each shark presented with the CS, but no US \\
\hline Day 19: Holding or release & $\begin{array}{l}\text { After trial completion, all sharks were weighed, some released and some held for } \\
\text { memory retention tests }\end{array}$ \\
\hline Day 39 or 59: Memory trials & $\begin{array}{l}\text { After } 20 \text { - or } 40 \text {-day absence from the set-up, sharks were moved into the } \\
\text { experimental tank, given } 24 \mathrm{~h} \text { to acclimatise and then presented with the CS }\end{array}$ \\
\hline Release & $\begin{array}{l}\text { All sharks were released on completion of final memory trials, weighed and then } \\
\text { fed to satiation }\end{array}$ \\
\hline
\end{tabular}

\section{Memory retention trials}

All sharks were tested for a response to the CS after 9 and 15 days of trials (i.e. experimental protocol Days 11 and 18). Some sharks were also held for retesting after 20 and 40 days $(n=7$ and 3, respectively) after completing the initial training period (i.e. experimental protocol Days 39 and 59). During non-experimental periods, sharks were held in outdoor holding tanks $(2,000 \mathrm{I})$ and fed to satiation every 2-3 days on frozen squid and pilchards.

\section{Data analysis}

For our first analysis, it was important to demonstrate that all test sharks were able to consume the US in a similar time and that they improved consistently across CS treatments and procedures (control, delay and trace). Thus, we could rule out these influences on learning. To do this, we calculated the median time taken to consume the US (see Table 2) for all sharks, each day, across treatments and procedures. If sharks did not consume the US, then a ceiling time of $180 \mathrm{~s}$ was implemented. We used the nonparametric Kendall rank correlation to determine whether sharks improved through time and compared trial Days 1, 5, 10 and 15 using Kruskal-Wallis rank-sum test. This was to ensure that sharks performed consistently at different stages during the experiments. 
No previous conditioning experiments have been completed on a heterodontiforme shark species so we were unsure how or whether the sharks would respond to the CS. However, Port Jackson sharks usually spend most of their time resting on the bottom (Powter and Gladstone 2009), so we predicted that anticipatory behaviour induced by the CS would, at the very least, lead to sharks changing positions and moving into the CS compartment. Classical conditioning experiments using Atlantic halibut, a sedentary Teleost fish, showed such subtle behavioural movements (Nilsson et al. 2010). Therefore, for all trials the location of the shark was recorded $5 \mathrm{~s}$ prior to CS onset, as a baseline comparison, and $5 \mathrm{~s}$ during the CS to allow time for a response. Sharks were recorded as having entered a compartment once their head and first dorsal fin had crossed the demarcation line. For each CS (air-bubble and light), we calculated the median number of trials per day individual sharks were present in the CS zone $5 \mathrm{~s}$ before and into CS onset. We also recorded whether the shark moved (turned towards the CS) at the CS onset (within $2 \mathrm{~s}$ ) and whether they displayed feeding type behaviours (i.e. biting) towards the CS (see behavioural ethogram; Table 2). These behaviours (median number) were then compared using a Friedman repeated-measures test across procedures (control, delay and trace) for CS (air-bubble and light) and then using Kruskal-Wallis rank-sum test at various experimental stages (trial Days 1, 5, 10 and 15). Post hoc tests with Bonferroni correction were also completed to identify whether any differences detected were between specific procedures. Nonparametric analyses were used throughout due to low replicates and non-normal data distributions. All statistical analyses were carried out in $\mathrm{R}$ version 2.12.1 (freeware available at www.r-project.org).

Table 2 Ethogram of behaviours measured

\begin{tabular}{|ll|}
\hline Behaviour & Measure \\
\hline Consumption time & Time (s) from US placement to consumption \\
Position 5 s pre-CS & Zone sector (1-4) \\
Position 5 s into CS & Zone sector (1-4) \\
Movement & Shark turns towards CS within 2 s of CS onset (yes/no) \\
Bite & Shark bites CS (yes/no) \\
\hline
\end{tabular}

\section{Results}

Learning trials

\section{Consumption times}

Port Jackson sharks consumed the US in $95 \%$ of trials (mean number of US consumed during trials \pm standard deviation $=85 \pm 5$ ) and improved across treatments and procedures in their times to consume the US, indicative of learning (Kendall' rank correlation, all $P<0.001$, Fig. 2). Importantly, these improvements were also relatively consistent (Fig. 2) as indicated by the lack of significant differences between US consumption time during the light CS across all procedures, for trial Days 1, 5, 10 and 15 (Kruskal-Wallis rank-sum test, $d f=2, P>0.1$ for all). This was also the case for our air-bubble CS for trial Days 1, 5 and 10 (Kruskal-Wallis rank-sum test, $d f=2, P>0.1$ for all), but not for trial Day 15 where we found a significant difference (Kruskal-Wallis rank-sum test, $X^{2}=6.15, d f=2, P=0.046$ ). Post hoc testing revealed that this was due to the difference between the control and trace procedures (pairwise $U$ test, $P=0.011)$. 


\section{Behaviours towards the CS}

Next, we compared the positions and behaviours (movement and bite, Table 2) of sharks across all trial days (1-15) and procedures (control, delay and trace). As expected, we detected no significant differences between the positions of sharks $5 \mathrm{~s}$ before CS onset for both CS across all procedures (Table 3; Fig. 3). However, $5 \mathrm{~s}$ into the CS shark positions were significantly different across procedures for both CS, indicating that they were attracted to the CS and changed their position accordingly (Table 3; Fig. 3). When comparing movement and biting across trial days, CS and procedures, we detected significant differences for our air-bubble but not light CS (Table 3; Fig. 4).

We further explored our data by assessing the positions and behaviour of sharks at various experimental stages (trial Days 1, 5, 10 and 15). When comparing trial Days 1 and 5, we detected no significant differences for all behaviours across procedures and for both CS, which was expected based on the low number of trial replicates at these early stages (Table 4; Figs. 3, 4). We also detected no differences, for trial Days 10 and 15, for the positions of sharks $5 \mathrm{~s}$ before the CS for all procedures and for both CS (Table 4); however, we did find significant differences between air-bubble CS trial Day 10 and light trial Day 15, for $5 \mathrm{~s}$ into the CS (Table 4; Fig. 3). Finally, when comparing the movement and biting behaviour of sharks, we found a significant difference at trial Day 10 for air-bubble CS movement, but no differences were detected at trial Days 10 and 15 for biting (both CS) (Table 4; Fig. 4). However, for our air-bubble CS, such differences were close to significance $(P<0.1)$ and were likely influenced by one control shark showing biting and movement towards the CS at these later experimental stages (Table 4; Fig. 4).

\section{Memory retention}

After 9 days of training, few sharks responded to the light or air-bubble CS (Table 5). After 15 days, however, we found that all sharks $(n=5)$ trained in our delay air-bubble CS responded with biting and movement, a result that was significantly different to control sharks trained to the same CS (Table 5). While we did see other sharks trained in different procedures respond to the CS during memory retention trials, none of these were significantly different to our control sharks (Table 5). In addition, we also tested two control, two delay and three trace sharks for a response 20 days (i.e. Day 39) after training for our airbubble CS. One delay shark moved and bit the CS, and one control shark moved towards the air-bubble CS. Furthermore, we tested one control shark and two delay sharks 40 days after training (i.e. Day 59), finding that one shark trained in our delay procedure responded with biting and movement.

\section{Discussion}

This study has demonstrated that juvenile $H$. portusjacksoni can reliably learn a delay classical conditioning regime and provides preliminary evidence for trace conditioning in an elasmobranch fish. Sharks trained on an air-bubble CS showed strong CRs, such as turning towards and biting the CS prior to the delivery of the US. In contrast, such behaviours were absent for individuals trained on a light CS, despite anticipatory positional changes during CS presentation that are indicative of a learnt CS-US association. These findings support results from other animal taxa that show CS choice can influence how animals respond to a CS announcing a US (Lieberman 1990; Rescorla 2008). We also found that two individuals trained to our air-bubble CS were able to retain such CS-US associations for 20 and 40 days after training as evidenced by them eliciting strong CRs. Taken together, these findings advance our knowledge of the learning capacities of elasmobranch fishes and emphasise the need for further research to understand how these processes evolved across the vertebrate lineage.

Pavlovian conditioning is typically described as a form of learning in which a neutral or arbitrary CS becomes associated with a US and, as a consequence, the CS comes to elicit a CR (Domjan 2005). 
However, the tendency to associate some stimulus combinations more readily than others varies across taxa, as a consequence of evolutionary selection for specialised sensory, receptor and associated apparatus (Seligman 1970; Lieberman 1990). Indeed, the choice of CS, together with its spatial and/or temporal relationship with the US, can influence the speed at which learning takes place and the nature and intensity of the CR (Lieberman 1990; Rescorla 2008). This is effectively a preparatory response for the forthcoming US and usually reflects natural behaviour when an animal is expecting prey to be delivered (Hollis 1984). For instance, archer fish (Toxotes chatareus) respond to a light CS above the surface by squirting water in it when paired with a US (Waxman and McCleave 1978), a behaviour that reflects their natural foraging strategy (Schuster et al. 2006). Similarly in this study, the CRs of $H$. portusjacksoni trained to the air-bubble CS typically included biting-type behaviours or vigorous respiratory pumping, which they are known to exhibit when foraging in sandy substrates (McLaughlin and O'Gower 1971; Powter et al. 2010). Interestingly, such behaviours were completely absent from individuals trained in the light CS despite sharks moving into the CS zone, indicative of anticipatory behaviour. If we consider wild juvenile $H$. portusjacksoni behaviour, it is likely that the absence of these biting-type CRs reflects differences in the biological relevance of the CS. H. portusjacksoni are nocturnal, feeding primarily on cryptic benthic prey (Powter et al. 2010); thus, vision probably does not play an important role in prey detection and capture (McComb and Kajiura 2008). Morphological evidence from other benthic fishes also supports this theory with a clear pattern for relatively reduced optic tectum (Kotrschal and Palzenberger 1992; Wagner 2002; Yopak 2012). Furthermore, H. portusjacksoni possess a large olfactory surface area, suggesting a reliance on olfaction (Schluessel et al. 2008). Alternatively, it is also possible that the lack of biting-type CRs towards the light CS was a result of intrinsic attractive qualities of the air-bubble CS, although we believe that this is unlikely as 4 of 5 sharks trained in the control procedure remained completely unresponsive to the CS. The only individual that did respond started biting the air-bubble CS at trial Day 9; we suspect that this shark learnt that the CS always preceded the US despite a randomised temporal gap of B300 s between the CS and US. A further explanation is that the CS differed in strength or intensity. The air-bubble CS produced acoustic, mechanical and visual stimuli, whereas the light CS emitted visual and electrical cues; thus, it is possible that the air-bubble CS was detected more rapidly. Future trials should consider varying the intensity or isolating particular stimulus outputs to enable us to understand more about the structure of the shark learning paradigm, i.e. biases in attention and how information is generalised.

Table 3 Results' summary of the behaviours of $\boldsymbol{H}$. portusjacksoni during learning experiments compared across different procedures (delay, D; control, C; and trace, T) for CS (light, L; and air-bubbles, AB)

\begin{tabular}{|c|c|c|c|c|c|c|}
\hline Behaviour & CS & $x^{2}$ & $P$ Value & Post hoc $D$ versus $C$ & Post hoc $T$ versus $C$ & Post hoc $T$ versus $D$ \\
\hline \multirow[t]{2}{*}{5 s pre-CS } & $\mathrm{L}$ & 2.78 & n.s. & n.s. & n.s. & n.s. \\
\hline & $A B$ & 1.72 & n.s. & n.s. & n.s. & n.s. \\
\hline \multirow[t]{2}{*}{$5 \mathrm{~s}$ into $\mathrm{CS}$} & $\mathrm{L}$ & 21.1 & $\star *$ & $\star *$ & n.s. & n.s. \\
\hline & $A B$ & 6.04 & * & * & * & * \\
\hline \multirow[t]{2}{*}{ Movement } & $\mathrm{L}$ & 0.78 & n.s. & n.s. & n.s. & n.s. \\
\hline & $A B$ & 8.45 & * & * & * & n.s. \\
\hline \multirow[t]{2}{*}{ Bite } & $\mathrm{L}$ & 0 & n.s. & n.s. & n.s. & n.s. \\
\hline & $A B$ & 13.18 & $\star *$ & $* *$ & $\star *$ & $* *$ \\
\hline
\end{tabular}



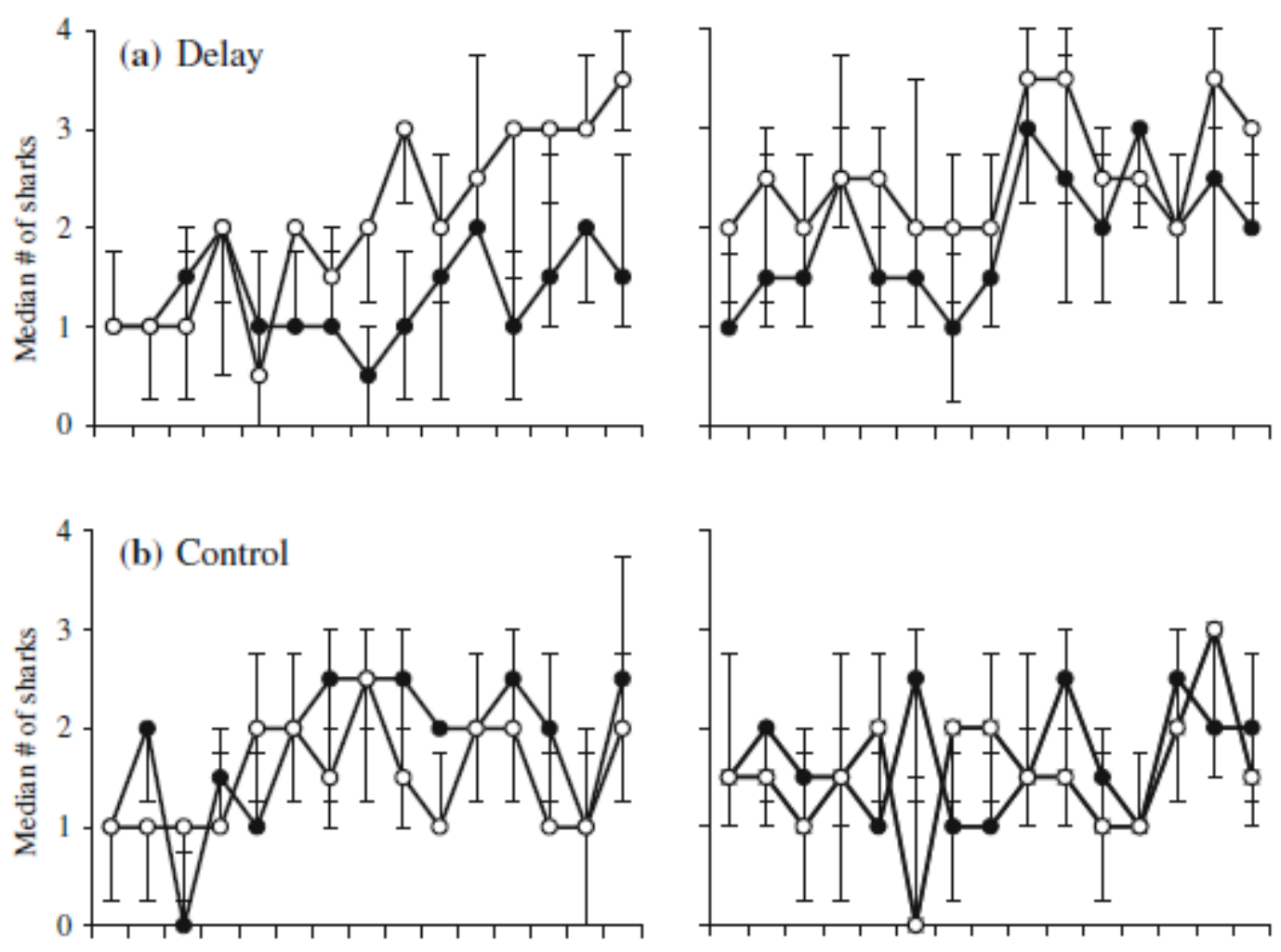

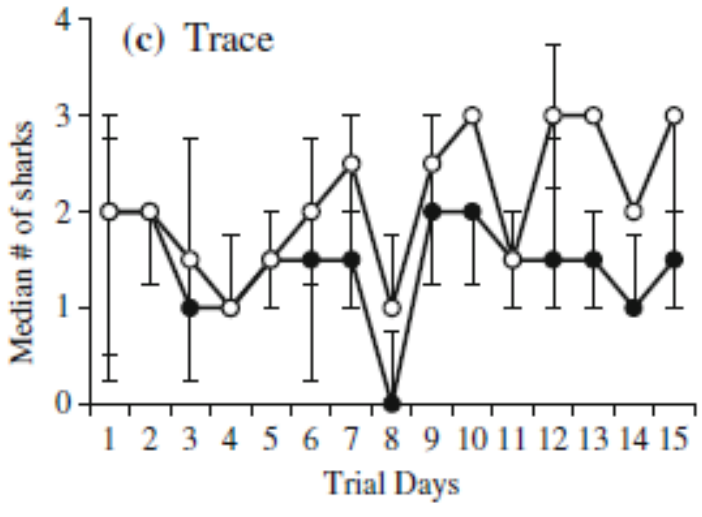

AIR-BUBBLES

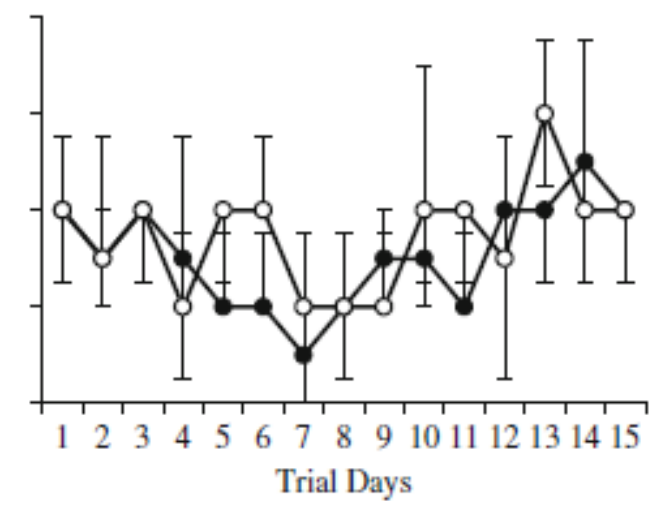

LIGHT

Fig. 3 Median ( \pm IQR) number of sharks in CS zone $5 \mathrm{~s}$ before CS onset (filled circles) and $5 \mathrm{~s}$ into the start of the CS (empty circles) in a delay, b control and c trace procedures. Left and right figures represent the airbubble and light $C S$, respectively. $n=5$ per procedure

H. portusjacksoni trained in our two CS in both delay and trace procedures exhibited varied CRs including biting, turning towards the CS and positional changes. According to Pavlov's (1927) stimulus substitution and classical stimulus response theory (Lieberman 1990), these are indicative of a sign-track response. It has been suggested that this type of response may be beneficial for animals that forage on prey that are sheltering under recognizable structures, such as stones or vegetation that could be associated as food and act as a CS (Purdy et al. 1999). The diet of juvenile $H$. portusjacksoni is dominated by benthic 
invertebrates, such as decapod crustaceans and echiurans (Powter et al. 2010). They have also been documented foraging in the sand substrate and on epiphytic organisms attached to seagrass blades (Powter and Gladstone 2008). This indicates that the strong sign-track response found here likely reflects their diet and foraging strategy. Furthermore, it is also expected to be advantageous for cruising predators, whose foraging behaviour involves orientation and approach to, and eventual chasing of the prey (Purdy et al. 1999; Nilsson et al. 2008a). H. portusjacksoni diet changes through ontogeny with adults feeding on more active and higher-trophic-level organisms, such as cephalopods (Powter et al. 2010). Thus, a strong sign-track response could also be beneficial as they reach maturity and transition to more active prey.
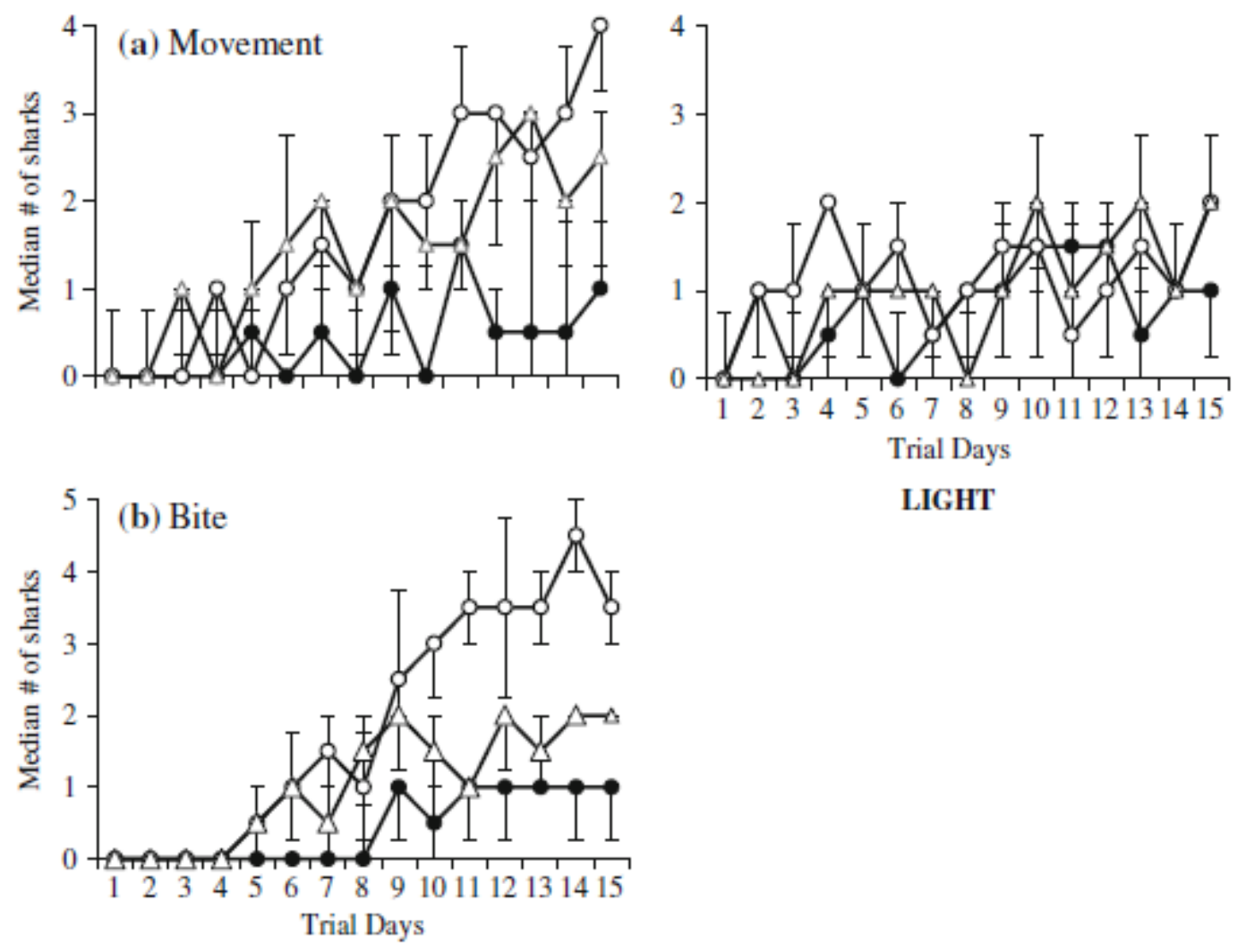

LIGHT

AIR-BUBBLES

Fig. 4 Median ( \pm IQR) number of sharks during delay (empty circles), control (filled circles) and trace (empty triangles) procedures that a turned and moved towards the CS within $2 \mathrm{~s}$ and $\mathrm{b}$ bit at the CS when it signalled. Left and right figures represent the air-bubble and light CS, respectively. Note sharks did not bite the light CS trials. $n=5$ per procedure

Like other animals, not all $H$. portusjacksoni trained in our trace procedure produced CRs or learnt a CSUS association. Two of five did not exhibit any biting-type behaviours towards the air-bubble CS, and sharks trained in our light CS trace procedure did not show any differences between behaviour during trials relative to the control sharks. It has been suggested that it is more cognitively demanding to learn an association with a temporal gap. In mammals and insects, trace conditioning recruits additional neural structures (Woodruff-Pak and Disterhoft 2008; Shuai et al. 2011). Interestingly unlike cod, we did not find that sharks trained in our trace procedure spent more time in the zone where the US was forthcoming 
during the time interval. This might be because $H$. portusjacksoni prefer to stay at a distance before the CS is detected. To explore this further, future trials should separate the positions of the CS and US. Sharks towards the end of training (i.e. Days 10 onwards) would regularly move directly to the US-CS zone after entering the experimental arena. Unfortunately, it is not possible to determine whether they were tracking the signal (CS) or the goal (US).

Table 4 Results' summary of the behaviours of Port Jackson sharks during learning experiments compared across different trials (1, 5, 10 and 15), procedures (delay, control and trace) and CS (light and air-airbubbles)

\begin{tabular}{|c|c|c|c|c|c|}
\hline \multirow[t]{2}{*}{ Behaviour } & \multirow[t]{2}{*}{ Trial Day \# } & \multicolumn{2}{|c|}{$x^{2}$} & \multicolumn{2}{|c|}{$P$ value } \\
\hline & & Light & Air-bubbles & Light & Air-bubbles \\
\hline \multirow[t]{4}{*}{5 s pre-CS } & 1 & 2.67 & 1.55 & n.s. & n.s. \\
\hline & 5 & 0.07 & 0.32 & n.s. & n.s. \\
\hline & 10 & 3.68 & 1.08 & n.s. & n.s. \\
\hline & 15 & 0.11 & 4.38 & n.s. & n.s. \\
\hline \multirow[t]{4}{*}{$5 \mathrm{~s}$ into CS } & 1 & 1.61 & 1.91 & n.s. & n.s. \\
\hline & 5 & 0.39 & 1.98 & n.s. & n.s. \\
\hline & 10 & 4.74 & 8.49 & 0.09 & * \\
\hline & 15 & 7.62 & 2.82 & $\star *$ & n.s. \\
\hline \multirow[t]{4}{*}{ Movement } & 1 & 2.53 & 1.07 & n.s. & n.s. \\
\hline & 5 & 0.52 & 2.30 & n.s. & n.s. \\
\hline & 10 & 1.85 & 7.66 & n.s. & $* *$ \\
\hline & 15 & 5.09 & 4.51 & 0.08 & 0.10 \\
\hline \multirow[t]{4}{*}{ Bite } & 1 & NA & 0 & NA & 1 \\
\hline & 5 & NA & 2.16 & NA & n.s. \\
\hline & 10 & NA & 5.45 & NA & 0.06 \\
\hline & 15 & NA & 4.7 & NA & 0.09 \\
\hline
\end{tabular}

Table 5 Results' summary of memory retention trials for Port Jackson sharks tested after 9 and 15 days of conditioning to procedures (delay, control and trace) and for CS (light and air-air-bubbles)

\begin{tabular}{|c|c|c|c|c|c|}
\hline \multirow[t]{2}{*}{ Procedure } & \multirow[t]{2}{*}{ \# Trial Days } & \multicolumn{2}{|c|}{ Bite } & \multicolumn{2}{|c|}{ Movement } \\
\hline & & Air-bubbles & Light & Air-bubbles & Light \\
\hline \multirow[t]{2}{*}{ Delay } & 9 & 1 & 0 & 1 & 0 \\
\hline & 15 & $5^{\star}$ & 0 & $5^{*}$ & 3 \\
\hline \multirow[t]{2}{*}{ Trace } & 9 & 0 & 0 & 2 & 3 \\
\hline & 15 & 1 & 0 & 0 & 3 \\
\hline \multirow[t]{2}{*}{ Control } & 9 & 0 & 0 & 0 & 1 \\
\hline & 15 & 1 & 0 & 1 & 0 \\
\hline
\end{tabular}


Comparing the learning capabilities of $H$. portusjacksoni with other species should be made with caution. Most studies on fishes test their subjects in groups and have used different procedures and inter-trial intervals, which likely affect the learning process (Nilsson et al. 2008a, b, 2010; Brown et al. 2011). However, it is noteworthy to mention the only other authoritative account of classical conditioning in an elasmobranch fish. Gruber and Schneiderman (1975) trained juvenile lemon sharks in an aversive paradigm finding reliable (95\%) CRs after approximately 60 trials. Such learning is comparable to $H$. portusjacksoni trained in our delay air-bubble CS with most sharks either biting, turning towards the CS or moving into the CS zone by Day 10 (trial 60). This suggests to us that benthic shark species, although regularly perceived as sluggish and slow, are capable of learning a CS-US association just as effectively as their more active larger-brained relatives (Yopak 2012).

All sharks were trained for six trials per day with $24 \mathrm{~h}$ between trial days. At our initial memory retention test after 9 days of training, only one shark trained in the delay procedure with air-bubble CS exhibited a strong CR. However, from trial Day 10 onwards, a number of sharks exhibited CRs regularly between experimental trial days, which suggests a memory window of at least $24 \mathrm{~h}$. This was further confirmed at our end of training memory retention trials where all sharks trained to the air-bubble CS responded through biting and movement. We also found preliminary evidence for relatively long-term memory with two of four sharks retaining the CS-US association after 20- and 40-day absences from the set-up. For other animals, memory retention is often discussed in the context of variable versus stable environments, with those from the latter expected to have better long-term memories. Indeed, for predators foraging in highly changeable prey fields, a memory of past locations where prey was previously abundant may be maladaptive, since to adapt rapidly to change, a shorter memory window is desirable for finding new prey locations (Mackney and Hughes 1995).

In conclusion, we have demonstrated that $H$. portusjacksoni, a benthic shark species, have the capacity to learn a classical conditioning procedure, display strong sign-tracked responses and have a memory window for two time-separated events of at least $24 \mathrm{~h}$, possibly up to 40 days. These cognitive abilities make ecological sense. As juveniles, Port Jackson sharks are continuous feeders known to exhibit longterm site fidelity (> 2 years) to specific seagrass beds (Powter and Gladstone 2009; Powter et al. 2010). This frequent use of particular areas coupled with regular non-intermittent feeding repeatedly exposes them to local prey organisms and associated habitats creating the conditions necessary for the evolution of impressive learning capabilities. Interestingly, recent morphological evidence indicates that benthic demersal elasmobranchs comprise the group with the smallest brains, reduced telencephalon and a smooth cerebellar corpus (Yopak 2012). Given that the latest findings in teleost fish show that cognitive ability can be dependent on brain size (Kotrschal et al. 2013), our study coupled with Kimber et al. (2013) highlights that sharks' cognitive capabilities are most likely understated.

\section{Acknowledgments}

T.L.G. was supported by an Endeavour Research Fellowship. CB was supported by an Australian Research Fellowship from the Australian Research Council. We thank Anthony Daly and Michael McMaster at the Merimbula Aquarium and Wharf Restaurant, NSW, Australia, for hosting the experiments and assistance with shark husbandry. We would also like to acknowledge the Sydney Aquarium Conservation Fund for funding support and Shannon Fantham and Pascal Gerraghty for assistance with and provision of the Port Jackson sharks. 


\section{References}

Aronson LR, Aronson FR, Clark E (1967) Instrumental conditioning and light-dark discrimination in young nurse sharks. Bull Mar Sci 17:249-256

Brown C, Laland K (2001) Social learning and life skills training for hatchery reared fish. J Fish Biol 59(3):471-493

Brown C, Laland K, Krause J (2011) Fish cognition and behaviour. Fish and aquatic resources series. Blackwell Publishers, Cambridge. doi:10.1002/9781444342536

Clark E (1959) Instrumental conditioning of lemon sharks. Science 130:217-218

Domjan M (2005) Pavlovian conditioning: a functional perspective. Annu Psychol Rev 56:179-206

Graeber RC, Ebbesson SO, Jane JA (1973) Visual discrimination in sharks without optic tectum. Science 180:413-415

Grubbs R (2010) Ontogenetic shifts in movement and habitat use. In: Carrier JC, Musick JA, Heithaus MR (eds) Sharks and their Relatives II: biodiversity, adaptive physiology, and conservation. CRC Press, Boca Raton, FL, pp 319-350

Gruber SH, Schneiderman N (1975) Classical conditioning of the nictitating membrane response of the lemon shark (Negaprion brevirostris). Behav Res Methods 7(5):430-434

Guttridge TL, Myrberg AA, Porcher IF et al (2009) Role of learning in shark behaviour. Fish Fish 10:450469

Guttridge TL, van Dijk S, Stamhuis EJ et al (2013) Social learning in juvenile lemon sharks, Negaprion brevirostris. Anim Cogn 16:55-64

Hollis KL (1984) Cause and function of animal learning processes. In: Marler P, Terrace HS (eds) The biology of learning. Dahlem Konferenzen. Springer, Berlin, pp 357-371

Kawecki TJ (2010) Evolutionary ecology of learning: insights from fruit flies. Popul Ecol 52(1):15-25

Kimber JA, Sims DW, Bellamy PH (2013) Elasmobranch cognitive ability: using electroreceptive foraging behaviour to demonstrate learning, habituation and memory in a benthic shark. Anim Cogn. doi:10.1007/s10071-013-0637-8

Kotrschal K, Palzenberger M (1992) Neuroecology of cyprinids: comparative, quantitative histology reveals diverse brain patterns. Environ Biol Fishes 33:135-152

Kotrschal A, Rogell B, Bundsen A et al (2013) Artificial selection on relative brain size in the guppy reveals costs and benefits of evolving a larger brain. Curr Biol 23(2):168-171

Last PR, Stevens JD (2009) Sharks and rays of Australia. CSIRO, Melbourne

Lieberman DA (1990) Learning: behaviour and cognition. Wadsworth, Belmont, California, p 500

Mackney PA, Hughes RN (1995) Foraging behaviour and memory window in sticklebacks. Behaviour 132:1241-1253

Malyukova IV, Rakich L, Kovachevich N (1983) Conditioned motor reactions in free-living elasmobranchs and bony fishes. Neurosci Behav Physiol 13:482-485

McComb DM, Kajiura SM (2008) Visual fields of four batoid fishes: a comparative study. J Exp Biol 211(4):482-490

McLaughlin RH, O'Gower AK (1971) Life history and underwater studies of a heterodont shark. Ecol Monogr 41:271-289

Nelson DR (1967) Hearing thresholds frequency discrimination and acoustic orientation in lemon shark Negaprion Brevirostris (Poey). Bull Mar Sci 17:741-768

Nilsson J, Kristiansen TS, Fosseidengen JE et al (2008a) Sign-and goal-tracking in Atlantic cod (Gadus morhua). Anim Cogn 11(4):651-659

Nilsson J, Kristiansen TS, Fosseidengen JE, Fernö A, van den Bos R (2008b) Learning in cod (Gadus morhua): long trace interval retention. Anim Cogn 11(2):215-222

Nilsson J, Kristiansen TS, Fosseidengen JE, Stien LH et al (2010) Learning and anticipatory behaviour in a "sit-and-wait" predator: the Atlantic halibut. Behav Process 83(3):257-266 
Nordgreen J, Janczak AM, Hovland AL et al (2010) Trace classical conditioning in rainbow trout (Oncorhynchus mykiss): what do they learn? Anim Cogn 13(2):303-309

O'Gower AK (1995) Speculations on a spatial memory for the Port Jackson shark (Heterodontus portusjacksoni)(Meyer)(Heterodontidae). Mar Freshw Res 46(5):861-871

Pavlov IP (1927) Conditioned reflexes (Anrep, G.V. trans). Oxford University Press, Oxford

Peach MB (2001) The dorso-lateral pit organs of the Port Jackson shark contribute sensory information for rheotaxis. J Fish Biol 59:696-704

Pearce JM, Bouton ME (2001) Theories of associative learning in animals. Annu Rev Psychol 52(1):111139

Perisse E, Waddell S (2011) Associative memory: without a trace. Curr Biol 21(15):579-581

Portavella M, Torres B, Salas C (2004) Avoidance response in goldfish: emotional and temporal involvement of medial and lateral telencephalic pallium. J Neurosci 24:2335-2342. doi:10.1523/JNEUROSCI.4930-03.2004

Powter DM, Gladstone W (2008) Demographic analysis of the Port Jackson shark Heterodontus portusjacksoni in the coastal waters of eastern Australia. Mar Freshw Res 59(5):444-455

Powter DM, Gladstone W (2009) Habitat-mediated use of space by Juvenile and Mating Adult Port Jackson Sharks, Heterodontus portusjacksoni, in Eastern Australia. Pac Sci 63(1):1-14

Powter DM, Gladstone W, Platell M (2010) The influence of sex and maturity on the diet, mouth morphology and dentition of the Port Jackson shark, Heterodontus portusjacksoni. Mar Freshw Res 61(1):74-85

Purdy JE, Roberts AC, Garcia CA (1999) Sign tracking in cuttlefish (Sepia officinalis). J Comp Psychol 113:443-449

Rescorla RA (2008) Within-subject renewal in sign tracking. Q J Exp Psychol 61(12):1793-1802

Schluessel V, Bleckmann H (2005) Spatial memory and orientation strategies in the elasmobranch Potamotrygon motoro. J Comp Physiol A 191:695-706

Schluessel V, Bleckmann H (2012) Spatial learning and memory retention in the grey bamboo shark (Chiloscyllium griseum). Zoology (in press)

Schluessel V, Bennett MB, Bleckmann H, Blomberg S, Collin SP (2008) Morphometric and ultrastructural comparison of the olfactory system in elasmobranchs: the significance of structure-function relationships based on phylogeny and ecology. J Morphol 269(11):1365-1386

Schneiderman N, Gormezano I (1964) Conditioning of the nictitating membrane of the rabbit as a function of CS-US interval. J Comp Physiol Psychol 57(2):188

Schuster S, Wöhl S, Griebsch M, Klostermeier I (2006) Animal cognition: how archer fish learn to down rapidly moving targets. Curr Biol 16(4):378-383

Seligman MEP (1970) On the generality of the laws of learning. Psychol Rev 77:406-418

Shuai Y, Hu Y, Qin H et al (2011) Distinct molecular underpinnings of Drosophila olfactory trace conditioning. Proc Natl Acad Sci 108(50):20201-20206

Sims DW (1996) The effect of body size on the standard metabolic rate of the lesser spotted dogfish. J Fish Biol 48(3):542-544

Speed CW, Field IC, Meekan MG, Bradshaw CJ (2010) Complexities of coastal shark movements and their implications for management. Mar Ecol Prog Ser 408:275-293

Tester AL, Kato S (1966) Visual target discrimination in blacktip sharks (Carcharhinus melanopterus) and grey sharks (C. menisorrah). Pac Sci 20:461-471

Tlusty MF, Andrew J, Baldwin K, Bradley TM (2008) Acoustic conditioning for recall/recapture of escaped Atlantic salmon and rainbow trout. Aquaculture 274:57-64

Wagner HJ (2002) Sensory brain areas in three families of deep-sea fish (slickheads, eels and grenadiers): comparison of mesopelagic and demersal species. Mar Biol 141:807-817

Waxman HM, McCleave JD (1978) Auto-shaping in the archer fish (Toxotes chatareus). Behav Biol 22(4):541-544 
Woodruff-Pak DS, Disterhoft JF (2008) Where is the trace in trace conditioning? Trends Neurosci 31:105112

Yopak KE (2012) Neuroecology of cartilaginous fishes: functional implications of brain scaling. J Fish Biol, Special Issue "The Current Status of Elasmobranchs: Biology, Fisheries, and Conservation" 80:1968-2023

Zion B, Barki A, Grinshpon J et al (2011) Retention of acoustic conditioning in St Peter's fish Sarotherodon galilaeus. J Fish Biol 78(3):838-847 